\title{
Performance and Noise Prediction of Marine Propeller Using Numerical Simulation
}

\author{
Agung Purwana ${ }^{1}$, I Made Ariana ${ }^{1}$, Wisnu Wardhana ${ }^{2}$, Dhimas Widhi $\mathrm{H}^{1}$
}

\begin{abstract}
One of the phenomenon appears on operation of marine propeller is noise. It could reduce performance of the propeller. In this study, numerical simulation is used to predict hydrodynamic performance and noise around non cavitation propellers. The formulation of RANS (Reynold Averaged Naiver Stokes) with turbulence model k- $\omega$ SST (Shear Stress Transport) and FWH (Ffowcs Williams-Hawkings formulation) is applied on the simulation. The noise is expressed in time-domain acoustic analogy as well as finite volume, and it is predicted at different receiver positions. The performance of propeller is predicted by MRF technique (Multiple Reference Frame). The $3 D$ model of B-series propeller with diameter of $D=250 \mathrm{~mm}$, blade number $Z=4$, pitch diameter ratio $P / D=1$, and area ratio $A e / A o=0.55$ is simulated on various advance coefficients $(J)$. Propeller rotation is simulated in range of 7.5 rps - 29rps and Re $=6.95 \times 104-3.36 \times 106$.
\end{abstract}

Keywords-Numerical Simulation, Propeller Performance, Noise.

\section{INTRODUCTION}

The propeller for propulsion must be carefully designed in accordance with the specific vessel. The design and development of propeller for submarine has a difference from the propellers for surface vessels. The most important requirement is low noise as well as propeller efficiency, so submarine propeller must be optimized in terms of noise and efficiency. Sound generated by a propeller is critical in underwater detection, and it is often related to the survivability of the vessels. In this paper we considered only non-cavitation marine propeller induced noise and propeller performances using numerical simulation. Performance and noise of marine propellers using numerical simulations have been investigated by researchers. Generation of a method by aero acousticians Ffowcs Williams-Hawkings (FWH) for calculation of noise of an arbitrary body moving in a fluid can be considered a mile stone in acoustic predictions [1]. With the development in computing power and numerical practice, this method became available also for hydro-acoustic predictions. Seol et. al. [2] investigated the noise of noncavitation propeller employing Boundary Element Methods

\footnotetext{
${ }^{1}$ Agung Purwana, I Made Ariana, and Dhimas Widhi $\mathrm{H}$ are with Department of Marine Engineering, Faculty of Marine Technology, Institut Teknologi Sepuluh Nopember (ITS), Kampus ITS Sukolilo, Surabaya 60111, Indonesia. E-mail: agpurwana@gmail.com; ariana@its.ac.id.

${ }^{2}$ Wisnu Wardhana is with Department of Ocean Engineering, Faculty of Marine Technology, Institut Teknologi Sepuluh Nopember (ITS), Kampus ITS Sukolilo, Surabaya 60111, Indonesia. E-mail: agpurwana@gmail.com.
}

(BEM) for the calculation of flow around propeller in timedomain and used FWH method to predict the far-field acoustics. Seol et. al. [3] extended their work to cavitation noise stage. They predicted cavity extent by the sheet cavity volume model and used the sheet cavity volume data and time dependent pressure as the input for the FWH equation to predict far-field acoustics [3]. Salvatore and Ianniello [4] published the preliminary results for cavitation propeller noise predictions. A hydrodynamic model for transient sheet cavitation on propellers in non-uniform inviscid flow was coupled with a hydro acoustic model based on the Ffowcs Williams-Hawkings equation. They demonstrated that noise predictions by the $\mathrm{FWH}$ equation were in satisfactorily agreement with those obtained by using the Bernoulli equation model. Barbarino and Casalino [5] studied and validated noise predictions for a NACA-0012 airfoil. Then they applied the same method to compute the broadband noise spectrum of an aircraft. On the other hand, after the 22nd ITTC Workshop on Propeller RANS/Panel Methods, a number of studies have been published [6]. Kawamura et. al. [7]) comparatively analyzed different turbulence models for the prediction of open water performance for a conventional propeller. Later $\mathrm{Li}$ published his results of estimating open water characteristics of a highly skewed model propeller employing $k-\omega$ turbulence model and validation study with experimental data [8]. The detailed literature review on the prediction of open water performance of propellers can be found in 26th ITTC [9]. Propeller noise prediction employing k- $\omega$ SST turbulence model transient solution is performed with second order implicit pressure based solver [10]. Velocity and pressure coupled SIMPLE algorithm.

Firstly, a validation study has been carried out for the prediction of open water propeller hydrodynamic characteristics of B4.55 screw propeller using numerical simulation comparison with the experimental results data given in Troost [11]. The method used for the noise prediction is given in Numerical Simulation Section.

\section{NUMERICAL SIMULATION}

\section{A. Method}

This work is carried out using numerical simulation, which has a built-in marine propeller hydrodynamic performance coefficient $(\mathrm{KT}, \mathrm{Kq}, \eta)$ with respect to advance coefficient $(\mathrm{J})$ and Re equation.

$$
J=\frac{V_{a}}{N D} ; K_{T}=\frac{T}{\rho N^{2} D^{4}} ; K_{q}=\frac{Q}{\rho N^{2} D^{5}}
$$




$$
\left(R_{e}\right)_{0.75 R}=\frac{C_{0.75 R^{*}} \sqrt{\left[V_{a}^{2}+(0.75 \pi n D)^{2}\right]}}{v}
$$

where $T, Q, N, D, \rho, V$ and $R e$ are the propeller thrust, torque, rotational speed, diameter, water density and advance velocity, and Reynold number of a characteristic radius (0.75R) respectively. The Ffowcs-Williams Hawkings equation uses generalized functions to extend the application of Lighthill's Acoustic Analogy, which is originally used to predict the aerodynamic noise. In present paper, the flow field is analyzed with finite volume method (FVM) and the propeller computational domain is cylindrical shape surrounding the propeller where a rotational cylinder with sufficient larger diameter than the propeller diameter enfolds the propeller in its cross section center and allows the fluid to pass by the model. The rotating zone was solved via Moving Reference Frame (MRF) which is shown in Figure 1 and 2, and then the time dependent flow field data are used as the input for Ffowcs Williams-Hawkings formulation to predict the far-field acoustics. Noise characteristics are presented according to noise sources and conditions. The developed flow solver is applied to the model propeller in uniform inflow. The simulation has been carried out by using the FW-H formulation (Ffowcs Williams Hawkings Equation) as discussed earlier. The FW-H equation is an inhomogeneous wave equation that is derived by manipulating the continuity equation and the Navier-Stokes equations [12]. For the numerical calculations ANSYS Fluent 16 was used to satisfy the following governing equation for continuity;

$$
\frac{\partial \rho}{\partial t}+\frac{\partial}{\partial x_{i}}\left(\rho v_{i}\right)=0
$$

where $x_{i}$ and $v_{i}$ are the tensor form of axial coordinates and velocities, respectively. Then the momentum equation becomes;

$$
\begin{gathered}
\frac{\partial\left(\rho v_{i}\right.}{\partial t}+\frac{\partial\left(\rho u_{i} u_{j}\right)}{\partial x_{j}}=-\frac{\partial p}{\partial x_{i}}+\frac{\partial}{\partial x_{j}}\left[\mu\left(\frac{\partial u_{i}}{\partial x_{j}}+\frac{\partial u_{j}}{\partial x_{i}}-\frac{2}{3} \delta_{i j} \frac{\partial u_{l}}{\partial x_{l}}\right)\right]+ \\
\frac{\partial}{\partial x_{j}}\left(-\rho \overline{u_{i}{ }^{\prime} u_{j}{ }^{\prime}}\right)
\end{gathered}
$$

where is $\delta_{i j}$ is Kronecker Delta and $-\rho \overline{u_{i}{ }^{\prime} u_{j}{ }^{\prime}}$ are the unknown Reynolds stresses.

$\frac{1}{a_{0}^{2}} \frac{\partial^{2} p^{\prime}}{\partial t^{2}}-\nabla^{2} p^{\prime}=\frac{\partial^{2}}{\partial x_{i} \partial x_{j}}\left\{T_{i j} H(f)\right\}-\frac{\partial}{\partial t}\left\{\left[P_{i j} n_{j}+\rho u_{i}\left(u_{n}-\right.\right.\right.$

$\left.\left.\left.v_{n}\right)\right] \delta(f)\right\}+\frac{\partial}{\partial t}\left\{\left[\rho_{0} v_{n}+\rho\left(u_{n}-v_{n}\right)\right] \delta(f)\right\}$

$u_{i}$ is fluid velocity component in the $x_{i}$ direction, $u_{n}$ is fluid velocity component normal to the surface $f=0, v_{i}$ is surface velocity component in the $x_{i}$ direction, $v_{n}$ is surface velocity component normal to the surface, $\delta(f)$ is Dirac delta function, $H(f)$ is Heaviside function, $T_{i j}$ is Lighthill stress tensor, $P_{i j}$ is compressive stress tensor, $p$ ' is sound pressure at the far-filed $\left(p^{\prime}=p-p 0\right)$. The solution to above Equation is obtained using the free-space Green's function. For the turbulence modelling, SST k- $\omega$ turbulence model is employed due to its good performance on wall bounded boundary layer flows [8].

RANS formulation is used with absolute velocity selection. Transient solution is performed with second order implicit pressure based solver. Velocity and pressure coupled via SIMPLE algorithm. Least Squares Cell Based is used for gradient and second order for pressure discretization. For Momentum, Turbulent Kinetic Energy and Specific Dissipation Rate calculations, second order upwind scheme is selected.

\section{B. B-series Propeller}

The B4.55 propeller has been analyzed in open water condition. The Open water experiments were performed in the Wageningen towing tank. Results were presented by Troost [11]. 3-D views and the main particulars of the B4.55 propeller are given in figure 1and in Table 1, respectively. In figure 1 the detailed mesh used for the study is presented.

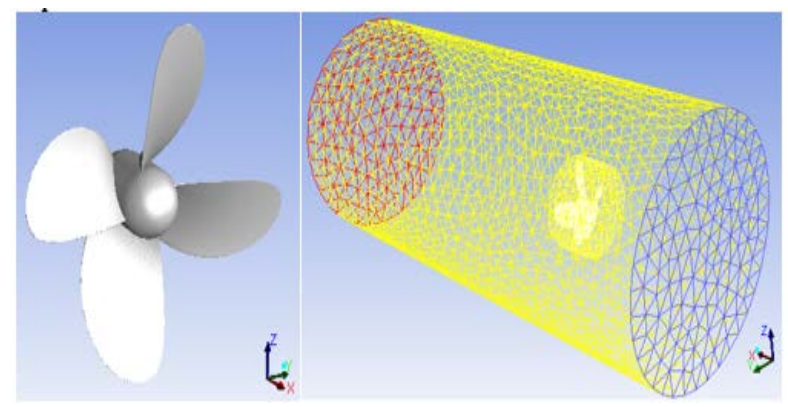

Figure 1. Geometry \& meshed model of the propeller with domain.

TABLE 1.

MAIN PARTICULARS OF PROPELLER.

\begin{tabular}{lc}
\hline \multicolumn{1}{c}{ Main particular } & B.4.55 \\
\hline Number of Blades, Z & 4 \\
Propeller Diameter, D & $0.25 \mathrm{~m}$ \\
Pitch Ratio at 0.7R, P/D & 1.0 \\
Expanded Blade Area Ratio, AE/A0 & 0.55 \\
Hub/Diameter Ratio & 0.21 \\
Rake & 15 degrees \\
Direction of rotation & Right handed \\
\hline \hline
\end{tabular}

In order to model the propeller in the fluid environment, the solution field is divided into dynamic and static cylindrical frames, as depicted in Figure 2. The dynamic frame simulates the propeller rotation and employs the Coriolis acceleration terms in the governing equations for the fluid. The dimensions of this frame are related to the propeller diameter. The static frame surrounds the dynamic frame. In this study, the domain size was chosen based on our previous work and some other numerical simulation works on marine propellers. The proposed dimensions proved to be the proper ones to achieve this end. The static frame is a cylinder with 3D diameter. The distance between the dynamic frame and inlet is nearly 2D, while it is nearly $5 \mathrm{D}$ for the outlet and dynamic frame. 


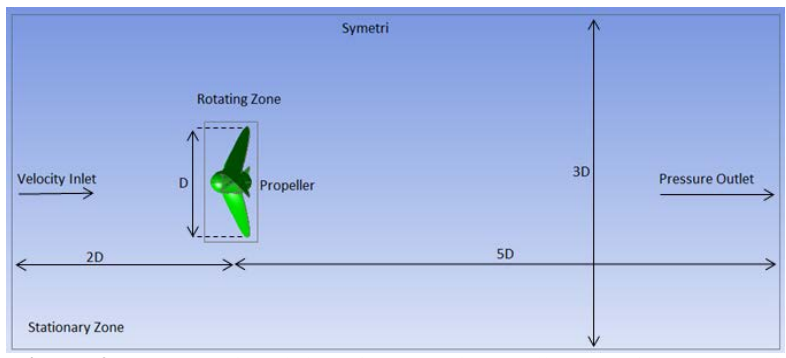

Figure 2. Computational domain around propeller (moving zone and stationary zone) and boundary conditions.

\section{Performance Prediction}

Open water performance calculations of propeller was carried out at $\mathrm{J}=0.4-0.9$. In addition, a mesh convergence study was performed for a propeller. In this study, different element sizes are considered. The best compromise between element size and accuracy has been obtained from the results of this work. A mesh independence study was performed meshes using 1291096 and 2959091 cells. The convergence of grid study can be seen in Table 2 with above grid properties in comparison with the experimental values at $\mathrm{J}=0.8$. Unstructured tetrahedral cells are used in stationary and rotating blocks for propeller and prismatic cells with the size of $0.00255792 \mathrm{D}$ are selected for the boundary layer on the propeller surface in figure 1. Number of cells for a propeller are 2.96 million

$$
\text { TABLE } 2 .
$$

THE RELATIVE ERROR OF NUMERICAL SIMULATION RESULTS WITH RESPECT TO THE EXPERIMENTS FOR GRID DEPENDENCY STUDY.

\begin{tabular}{lccc}
\hline \hline Number of cells & KT (\%) & 10KQ (\%) & $\boldsymbol{\eta} \mathbf{( \% )}$ \\
\hline 1291096 & 9.100 & 7.882 & 1.322 \\
2959091 & 7.719 & 7.633 & 1.273 \\
\hline \hline
\end{tabular}

\section{Noise Prediction in Open Water}

After the steady computations which were performed for the performance predictions of propeller, calculations were carried out transiently to predict the noise characteristics. In this study we studied non-cavitation noise in order to find the ranges of the Sound Pressure Levels, its development and the effect of non-cavitation noise on the SPL's. In Table 3, $N$ is rotational speed, $V a$ is axial velocity of flow, $\rho$ is density of water, ao is sound velocity and Pref is reference pressure in underwater. In this numerical simulation 3 hydrophones are used for extracting the Sound Pressure Levels (SPLs). The Position of Hydrophones and their coordinates are shown in Figure.4 and Table 4, respectively.

TABLE 3.

PARAMETERS OF FLOW AND ACOUSTIC CONDITIONS.

\begin{tabular}{ccccccc}
\hline \hline $\mathbf{J}$ & $\begin{array}{c}\mathbf{V a} \\
(\mathbf{m} / \mathbf{s})\end{array}$ & $\begin{array}{c}\mathbf{N} \\
(\mathbf{r p s})\end{array}$ & $\mathbf{R e}$ & $\begin{array}{c}\boldsymbol{\rho} \\
\left(\mathbf{k g} / \mathbf{m}^{3}\right)\end{array}$ & $\begin{array}{c}\mathbf{a o} \\
\mathbf{( m / s})\end{array}$ & $\begin{array}{c}\text { Pref } \\
(\mathbf{P a})\end{array}$ \\
\hline 0.4 & 0.75 & 7.5 & $6.95 \mathrm{e}+04$ & 998.2 & 1500 & $10^{-6}$ \\
0.4 & 1.5 & 15 & $2.11 \mathrm{e}+05$ & 998.2 & 1500 & $10^{-6}$ \\
0.6 & 1.125 & 7.5 & $1.24 \mathrm{e}+05$ & 998.2 & 1500 & $10^{-6}$ \\
0.6 & 2.25 & 15 & $4.3 \mathrm{e}+05$ & 998.2 & 1500 & $10^{-6}$ \\
0.8 & 1.5 & 7.5 & $2.01 \mathrm{e}+05$ & 998.2 & 1500 & $10^{-6}$
\end{tabular}

\begin{tabular}{ccccccc}
0.8 & 3.0 & 15 & $7.35 \mathrm{e}+05$ & 998.2 & 1500 & $10^{-6}$ \\
0.8 & 4.4 & 22 & $1.55 \mathrm{e}+06$ & 998.2 & 1500 & $10^{-6}$ \\
0.8 & 5.8 & 29 & $2.66 \mathrm{e}+06$ & 998.2 & 1500 & $10^{-6}$ \\
0.9 & 1.6875 & 7.5 & $2.47 \mathrm{e}+05$ & 998.2 & 1500 & $10^{-6}$ \\
0.9 & 3.375 & 15 & $9.21 \mathrm{e}+05$ & 998.2 & 1500 & $10^{-6}$ \\
0.9 & 4.950 & 22 & $1.95 \mathrm{e}+06$ & 998.2 & 1500 & $10^{-6}$ \\
0.9 & 6.525 & 29 & $3.36 \mathrm{e}+06$ & 998.2 & 1500 & $10^{-6}$ \\
\hline \hline
\end{tabular}

TABLE 4.

COORDINATES OF HYDROPHONES.

\begin{tabular}{cccc}
\hline \hline Name & X-Coord (m) & Y-Coord (m) & Z-Coord (m) \\
\hline Hydrophone 1 & 1.0 & 0.375 & 0 \\
Hydrophone 2 & 1.0 & 0 & 0.375 \\
Hydrophone 3 & 1.0 & 0 & 0 \\
\hline \hline
\end{tabular}

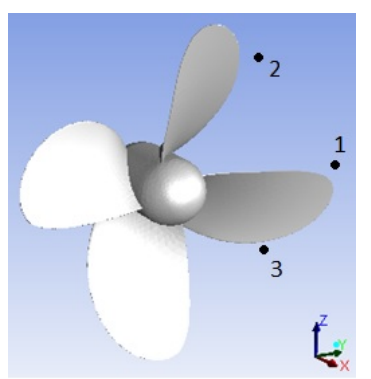

Figure 4. Position of Hydrophones for Numerical Simulation.

\section{RESULT AND ANALYSIS}

\section{A. Propeller performances}

The accurateness of prediction for the blade surface pressures is directly related to that of the propeller noise. Therefore, the result is validated with the experimental result in the no-wake flow condition. Figures 5 shows the pressure distribution on propeller at an advance coefficient of $J=0.8$. High pressure is on the face side and low pressure is on the back side. Also, the contour of flow velocity path lines at downstream of the propeller at an advance coefficient of $\mathrm{J}=0.8$ are shown in figure 6 .

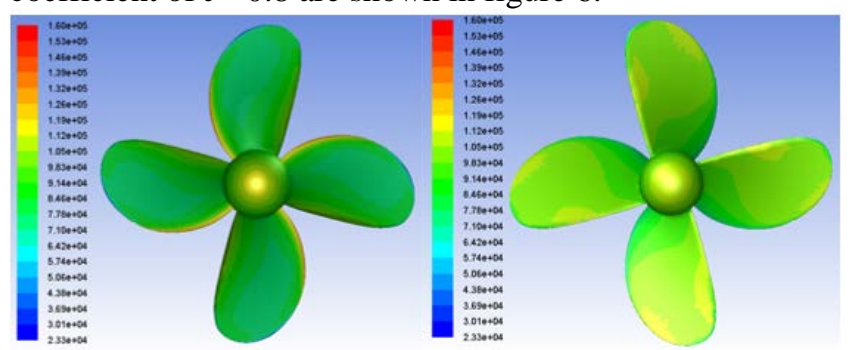

Figure 5. Pressure distribution on face (left) and back (right) of the propeller at $\mathrm{J}=0.8-29$ rps.

RANS calculations captured very well the values of thrust and torque at given advanced ratios. Figure 9 shows the comparison of thrust and torque of the propeller with respect to the advance coefficient $\mathrm{J}$. 


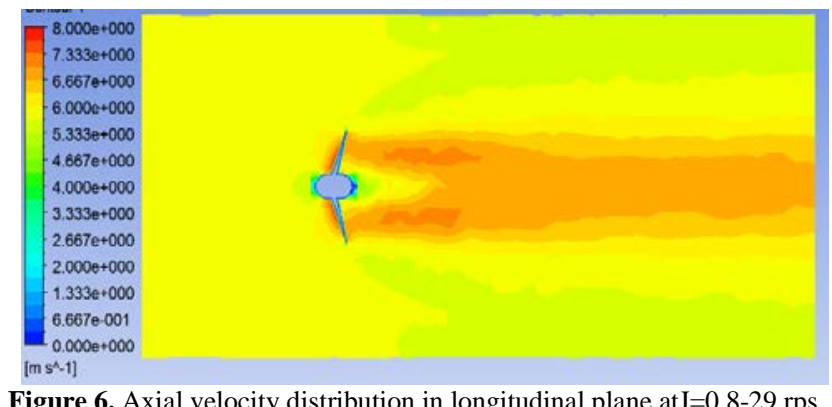

Figure 6. Axial velocity distribution in longitudinal plane at $J=0.8-29 \mathrm{rps}$

The thrust coefficient KT and the torque coefficient KQ decrease when the advance coefficient increase, because the effective angle of attack for the blade is inversely proportional to the advance coefficient at the constant rotating speed. Table 5 shows the numerical results for thrust and torque which have a good agreement with the data experiment results in the overall range of the advance coefficient

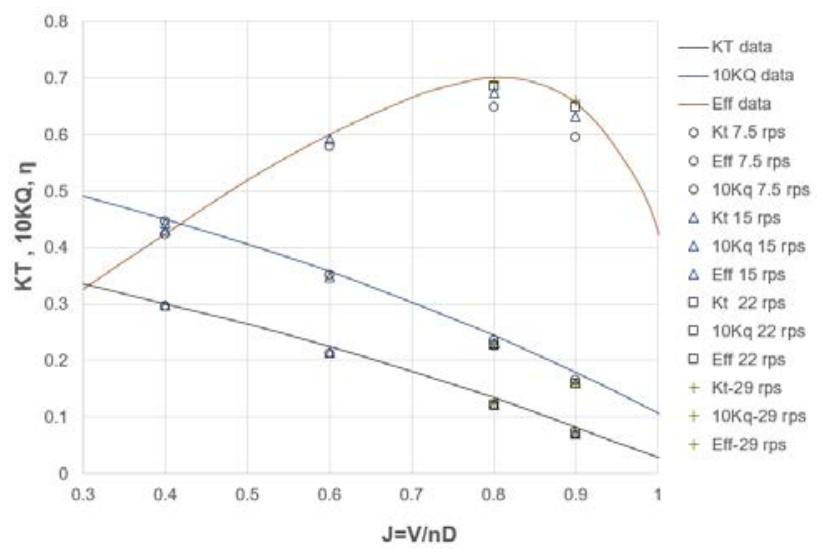

Figure 7. Comparison of thrust, torque and efficiency for propeller TABLE 5.

THE RELATIVE ERROR OF NUMERICAL SIMULATION RESULTS WITH RESPECT TO THE DATA EXPERIMENTS FOR PROPELLER.

\begin{tabular}{ccccc}
\hline \hline $\mathbf{J}$ & $\mathbf{N}(\mathbf{r p s})$ & $\mathbf{\Delta K T}(\%)$ & $\Delta \mathbf{1 0 K Q}(\%)$ & $\Delta \boldsymbol{\eta}(\%)$ \\
\hline 0.4 & 7.5 & 1.433 & 0.867 & 0.706 \\
0.4 & 15 & 0.733 & 1.733 & -0.941 \\
0.6 & 7.5 & 5.644 & 1.955 & 3.667 \\
0.6 & 15 & 4.533 & 3.045 & 1.500 \\
0.8 & 7.5 & 10.075 & 4.000 & 7.684 \\
0.8 & 15 & 8.571 & 6.163 & 3.980 \\
0.8 & 22 & 7.970 & 7.102 & 2.413 \\
0.8 & 29 & 7.719 & 7.633 & 1.273 \\
0.9 & 7.5 & 15.854 & 7.151 & 9.370 \\
0.9 & 15 & 13.537 & 10.279 & 3.734 \\
0.9 & 22 & 12.683 & 11.620 & 1.144 \\
0.9 & 29 & 12.073 & 12.514 & -0.531 \\
\hline \hline
\end{tabular}

\section{B. Propeller Noise}

Noise characteristics are presented according to the noise sources and operation conditions of the propeller. According to the results non-cavitation noise is incepted by increasing of flow velocity and propeller rotation speed.
The graph bellow represents the convergence history of the propeller sound pressure levels. The convergence criteria are considered as the difference between the values of the succeeding and preceding which are in the range of $10^{-4}$.

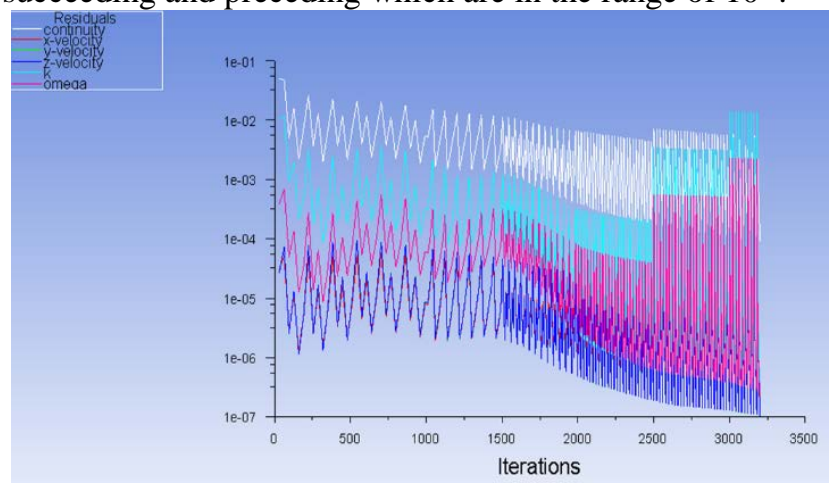

Figure 8. Convergence graph at $\mathrm{J}=0.8-29 \mathrm{rps}$

Acoustic graph in the following figure 9, 10,11 and 12 represent the Sound Pressure Level (SPLs) of the propeller resulted from various hydrophones placed at various position for different operating condition flows velocity and rotational speed of propeller.

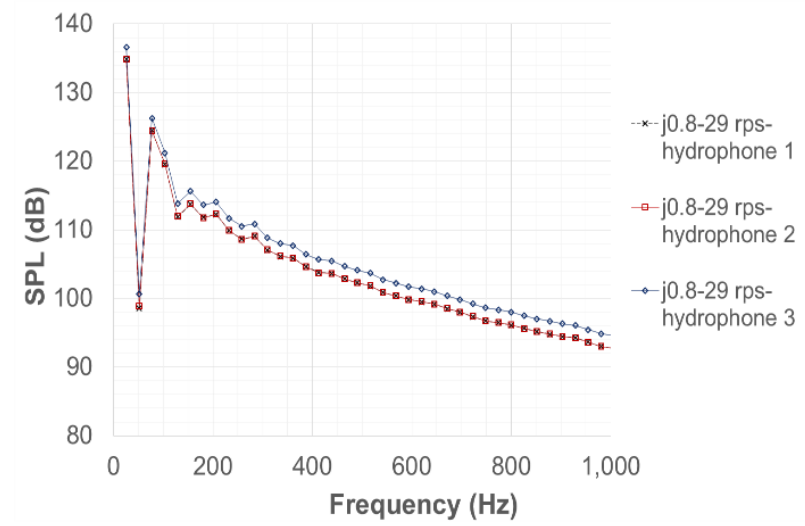

Figure 9. Noise prediction graph up to $1000 \mathrm{~Hz}$ (SPLs(dB) for hydrophone 1, 2, 3 Pref $(\mathrm{Pa})=10^{-06}$ at $\mathrm{J}=0.8-29$ rps.

The result of experiments shows that the SPL increase with the higher value of $J$ as we can see in figure 10, 11 and 12. This phenomenon is caused by the increasing of the rotational speed of the propeller as well as the velocity of fluids that flows through the propeller. Higher rotational speed of propeller and the fluids that flows through the propeller cause turbulence which generate a higher propeller noise.

Additionally, the high rotational speed of propeller induces a propeller cavitation. According Bernoulli's Law, the flow of the water through the propeller blades causes higher pressure in the face than in the back of propeller. As the rotation of propeller increases, this pressure difference becomes much higher. Low pressure induces bubbles as the result of boiling of water in the back of propeller. The bubbles are collapsed as it impacts to the back of propeller which significantly contribute to induce the noise of propeller.

As can be seen in the figure 9, the SPL resulted on hydrophone 3 which is positioned in the $\mathrm{x}$-axis is higher compared with the result of the SPL on hydrophones 1 and 
2 which are positioned on the right and top side at j-0.8 29 rps. This is because the turbulence and cavitation appear more significant in the position where the hydrophone 3 are located

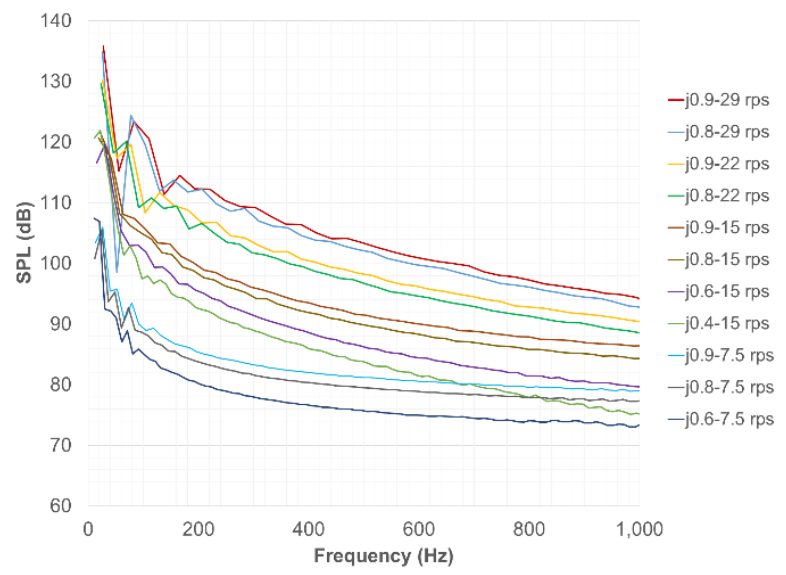

Figure 10. Noise prediction graph up to $1000 \mathrm{~Hz}$ (SPLs(dB)for hydrophone 1 Pref $(\mathrm{Pa})=10^{-06}$ for different operating condition velocities and rotation.

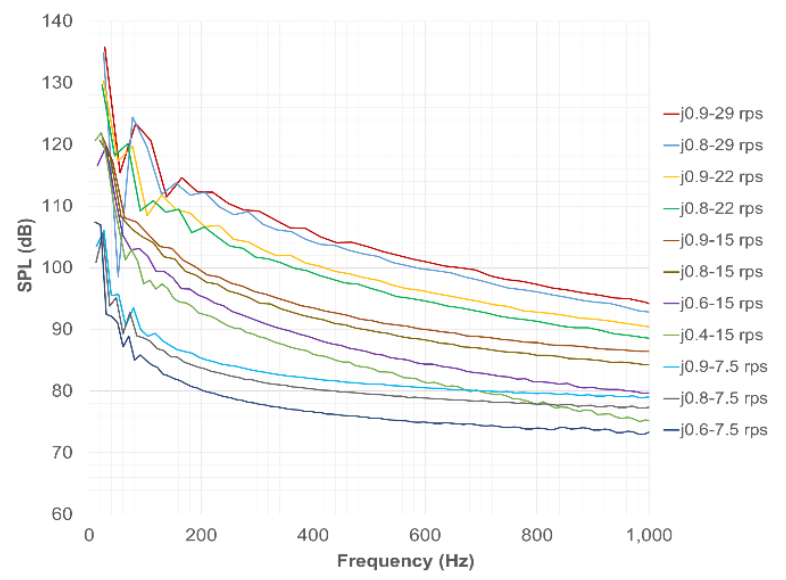

Figure 11. Noise prediction graph up to $1000 \mathrm{~Hz}$ SPLs(dB) for hydrophone $2 \mathrm{Pref}(\mathrm{Pa})=10^{-06}$ for different operating condition velocities and rotation.

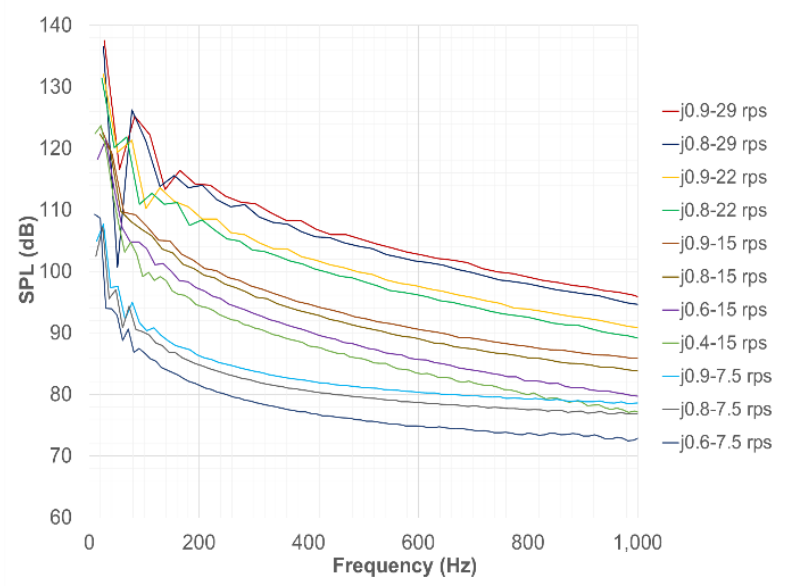

Figure 12. Noise prediction graph up to $1000 \mathrm{~Hz}$ (SPL(dB) for hydrophone 3 Pref $(\mathrm{Pa})=10^{-06}$ for different operating condition velocities and rotation.

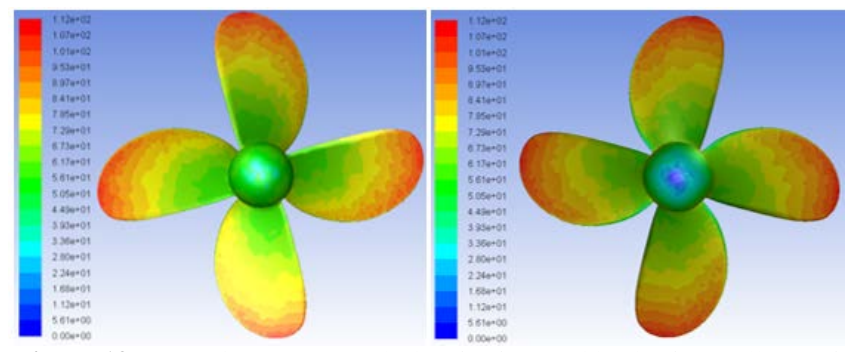

Figure 13. Acoustic Power Level (dB) for face and back of propeller. Ref acoustic power $(\mathrm{w})=1 \mathrm{e}^{-20}$ at $\mathrm{J}=0.8-29$ rps.

The contour of acoustic power level of the propeller can be predicted for all operational conditions. as can be seen in Figure.13. This figure shows the case of the operational propeller at $\mathrm{J}=0.8-22$ rps. In this figure, the ranges of Acoustic Power Level (dB) is shown using the colour differences. The power level countour which is the tip at face side and back is higher compared to the hub and root of propeller

\section{CONCLUSION}

This paper investigated the hydrodynamic and noise phenomenon of a propeller in some operating conditions. A finite volume based RANS solver has been used to evaluate the performance of these systems. The result of this paper shows that the numerical are in good agreement with the experimental data. Propeller speed of 7.5,15, and 22 with flows velocity of $0.75 \mathrm{~m} / \mathrm{s}-4.95 \mathrm{~m} / \mathrm{s}$ for all noise prediction. The result of experiments shows that the overall SPLs for hydrophone 3 is higher than hydrophone 1 and 2 since since the higher turbulence and cavitation in the location of hydrophone 3. The ranges of SPLs increase with the increasing of flows velocity and rotational speed of propeller, since the increasing of both parameter affect on the increasing of turbulence and cavitation. The result showed that in the process of initiation of SPLs, the increasing effect of rotational speed of propeller was stronger than flow velocity at low frequency $(\mathrm{J}=0.4-15 \mathrm{rps}$ compared $\mathrm{J}=0.8-7.5 \mathrm{rps}$ ). The obtained results can be used to optimize the operational parameter of derivate pattern of noise radiation at underwater vehicle.

\section{ACKNOWLEDGEMENT}

This work was financially supported by the Ministry of Research, Technology and Higher Education of Indonesia.

\section{REFERENCES}

[1] J. E. F. Williams and D. L. Hawkings, "Sound Generation by Turbulence and Surfaces in Arbitrary Motion," Philos. Trans. R. Soc. A Math. Phys. Eng. Sci., vol. 264, no. 1151, pp. 321-342, May 1969.

[2] H. Seol, B. Jung, J.-C. Suh, and S. Lee, "Prediction of NonCavitating Underwater Propeller Noise,” J. Sound Vib., vol. 257, no. 1, pp. 131-156, 2002.

[3] H. Seol, J.-C. Suh, and S. Lee, "Development of hybrid method for the prediction of underwater propeller noise,” J. Sound Vib., vol. 288, no. 1, pp. 345-360, 2005.

[4] F. Salvatore and S. Ianniello, "Preliminary results on acoustic modelling of cavitating propellers," Comput. Mech., vol. 32, no. 4, pp. 291-300, Dec. 2003.

[5] M. Barbarino and D. Casalino, "Hybrid Analytical/Numerical 
Prediction of Propeller Broadband Noise in the Time Domain,” Int. J. Aeroacoustics, vol. 11, no. 2, pp. 157-175, Jun. 2012.

[6] ITTC, "The Specialist Committee on Azimuthing Podded Propulsion," in Proceedings of 25th ITTC - Volume II, 2008, pp. 563-603.

[7] T. Kawamura, T. Watanabe, Y. Takekoshi, M. Maeda, and H. Yamaguchi, "Numerical Simulation of Cavitating Flow around a Propeller,” J. Soc. Nav. Archit. Japan, vol. 2004, no. 195, pp. 211219, 2004.

[8] D.-Q. LI, "Validation of RANS predictions of open water performance of a highly skewed propeller with experiments -
ScienceDirect,” J. Hydrodyn. Ser. B, vol. 18, no. 3, pp. 520-528, 2006.

[9] ITTC, "The Specialist Committee on Computational Fluid Dynamics," in Proceedings of 26th ITTC - Volume II, 2011.

[10] M. C. Özden, A. Y. Gürkan, Y. A. Özden, T. G. Canyurt, and E. Korkut, "Underwater radiated noise prediction for a submarine propeller in different flow conditions," Ocean Eng., vol. 126, pp. 488-500, Nov. 2016.

[11] L. Troost, Open-water Test Series with Modern Propeller Forms. North East Coast Institution of Engineers and Shipbuilders, 1938.

[12] ANSYS Inc, ANSYS FLUENT 12.0 Theory Guide. ANSYS, Inc., 2009. 